\title{
Da Europa à América: os ITINERÁrios das PRIMEIRAS ObRas de Primo LeVI PUBLICADAS NO BRASIL
}

\author{
Dall'Europa all'America: i Percorsi delle Prime \\ Opere di Primo Levi Pubblicate in Brasile
}

\author{
From Europe to America: the Itineraries of the \\ First Works of Primo Levi Published in Brazil
}

\author{
Aislan Camargo Maciera* \\ Lucia Wataghin"*
}

RESUMO: Primo Levi (1919-1987) é um dos grandes autores do panorama literário universal da segunda metade do século XX. Considerado o principal nome da literatura sobre a Shoah, figura emblemática da memória sobre os campos de concentração e extermínio nazifascistas. Sua obra é um monumento narrativo e reflexivo sobre a condição do prisioneiro no Lager, mas, além disso, sobre a própria condição humana. Escritor atemporal, que se faz cada vez mais necessário em um contexto no qual as representações do fascismo ainda teimam em sobreviver. Considerando o grande alcance que os escritos de Levi tem nos diversos campos do conhecimento, bem como o itinerário que sua obra seguiu até o momento presente, nosso artigo tem a intenção de estabelecer um panorama sobre a recepção e a fortuna crítica das duas primeiras obras de Primo Levi publicadas no Brasil: É isto um homem? e Os afogados e os sobreviventes. Cuidar da recepção dos escritos de Primo Levi e da fortuna crítica por eles gerada é poder determinar o quanto o autor foi traduzido e acolhido nos mais diversos ambientes culturais de chegada e, estudando o processo que conduziu a essa acolhida, poder compreender o valor universal de sua literatura.

PALAVRAS-CHAVE: Primo Levi; Literatura de testemunho; Tradução; Recepção; narrativa italiana do século XX.

\footnotetext{
* Universidade de São Paulo (USP)

aislan@usp.br - (ORCID: 0000-0002-9970-8222)

** Universidade de São Paulo (USP)

luciawataghin@gmail.com - (ORCID: ]0000-0001-8536-1064)

DOI: http://dx.doi.org/10.11606/issn.2238-8281.v0i41p98-111
} 
RIASSUNTO: Primo Levi (1919-1987) è uno dei grandi autori del panorama letterario universale del secondo Novecento. Considerato il nome principale della letteratura sulla Shoah, figura emblematica della testimonianza sui campi di concentramento e sterminio nazifascisti. La sua opera è un monumento narrativo e riflessivo sulla condizione del prigioniero in Lager, ma, soprattutto, sulla condizione umana stessa. Scrittore sempre più necessario, in un contesto in cui le rappresentazioni del fascismo insistono ancora a sopravvivere. Considerando l'ampia portata che gli scritti di Levi hanno nei vari campi del sapere, nonché l'itinerario che la sua opera ha seguito fino ad oggi, il nostro articolo si propone di stabilire un panorama della ricezione e della fortuna critica delle prime due opere di Primo Levi tradotte in Brasile: É isto um homem? e Os afogados e os sobreviventes. Osservare la ricezione degli scritti di Primo Levi e la fortuna critica da essi generata è poter determinare quanto l'autore sia stato tradotto e accolto nei più diversi ambienti culturali di arrivo $\mathrm{e}$, studiando il processo che ha portato a tale accettazione, riuscire a comprendere il valore universale della sua letteratura.

PAROLE CHIAVE: Primo Levi; Letteratura di testimonianza; Traduzione e ricezione; Narrativa italiana del XX secolo

ABSTRACT: Primo Levi (1919-1987) is one of the greatest authors of the universal literary panorama of the second half of the 20th century. He is considered the main name of the Shoah literature and an emblematic figure in the memory of the Nazi-Fascist concentration and extermination camps. His work is a narrative and reflective monument about the condition of the prisoner in the Lager, but, moreover, about the human condition itself. A timeless writer who becomes increasingly necessary in a context in which the fascism representations still persist in surviving. Considering the wide scope that Levi's writings have in the various fields of knowledge, as well as the itinerary that his work has followed to the present moment, our article intends to establish an overview of the reception and the critical fortune of the first two works that Primo Levi published in Brazil: É isto um homem? and Os afogados e os sobreviventes. To deal with Primo Levi's reception and writings, and the critical fortune generated by them, is to be able of determining how the author was translated and welcomed in the most diverse cultural environments. By studying the whole process, it is possible to understand the universal value of his literature.

KEYWORDS: Primo Levi; Testimonial literature; Translation; Reception; Italian narrative of the twentieth century. 


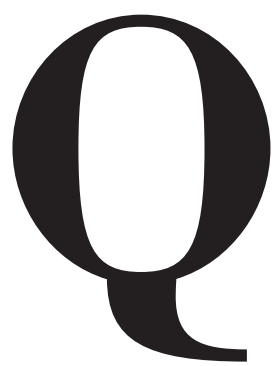

ualquer estudo sobre a recepção da obra literária não pode prescindir, em primeiro lugar, de uma análise dos contextos culturais e linguísticos conectados à passagem de uma língua a outra, um tema sobre o qual o próprio Primo Levi trabalhou ao longo de sua carreira de escritor, e não somente para favorecer uma adequada e exata compreensão de seus escritos em contextos não italianos, mas também como função que desempenhou. Levi traduziu para o italiano, pela editora Einaudi, desde obras de divulgação científica e ensaios, até clássicos da literatura, como Kafka. O autor sempre fez questão de trocar informações e estar em contato com os tradutores de sua obra, e o caso mais emblemático e de mais destaque foi o permanente contato que ele estabeleceu com Heinz Riedt, tradutor de Se questo è un uomo para o alemão Ist das ein Mensch?, publicado em 1961.

Levi estudou alemão durante os anos do liceu. Depois o aperfeiçoou ao longo da vida universitária e profissional, já que, naquele tempo, o alemão era praticamente um idioma obrigatório para um químico. No período em que esteve no Lager, Levi fez uso daquilo que aprendera e, inclusive, esse é um dos fatores aos quais atribui sua sobrevivência: entendia as ordens e comandos; foi a língua na qual realizou o exame de química para entrar no laboratório da Buna - outro fator, segundo ele, responsável por sua sobrevivência.

A tradução de Se questo è un uomo para a língua de Goethe chama a atenção de Levi: ao mesmo tempo em que o deixa "tomado por uma emoção nova e violenta" e com a "sensação de ter vencido uma batalha" (LEVI, 2016, p. 137), o deixa inquieto, desconfiado. Sua preocupação era, como muitas vezes declarou, que o leitor alemão realmente compreendesse aquilo que ele escrevera sobre a sua experiência como prisioneiro dos nazistas. Fato é que, conhecendo suficientemente o alemão para acompanhar o trabalho do tradutor, ele verificou capítulo por capítulo da tradução e ficou muito satisfeito com o resultado, tanto que intercedeu junto à Einaudi para que Riedt fosse o tradutor de todos os seus livros na Alemanha ${ }^{1}$.

O cuidado de Levi com as traduções de sua obra se justifica. Trata-se de um autor que sempre buscou na clareza e na objetividade a essência de seus escritos. Domenico Scarpa destaca que Levi tem uma fidelidade "radical" à palavra e à linguagem, o que acaba lhe conferindo uma exatidão e uma lealdade ao significado dos termos que utiliza. Isso se mantém em toda sua obra, de forma que, "se Levi usa constantemente uma palavra em uma mesma acepção, essa palavra aparece com o mesmo sentido a cada nova ocorrência, em toda a sua obra" (GOLDSTEIN;

1 Heinz Reidt era um italianista: especialista em Carlo Goldoni, conhecia o dialeto vêneto, e estudara literatura italiana na Universidade de Pádua. Ele havia saído da Alemanha para não se apresentar ao exército, e se dirigido à Itália, onde lutou ao lado dos "partigiani”. O pedido de Levi, para que Reidt fosse seu tradutor exclusivo, não foi atendido, porém. Sua obra em alemão conta com vários tradutores diferentes: Barbara Kleiner, Moshe Kahn, Joachim Meinert, entre outros. 
SCARPA, 2015, p. 45). Mais: tal palavra deve ser traduzida da mesma maneira, mantendo-se fiel à original, a cada nova ocorrência, de livro em livro, de escrito em escrito. Ou seja, as traduções devem salvaguardar a coerência de Levi. Em outro ponto, o crítico, fazendo referência ao conhecido artigo de Levi, "Traduzir e ser traduzido", presente em $O$ ofício alheio, e ao prefácio de Se questo è un uomo, destaca que, para Levi, "a atividade do tradutor é o outro lado, o oposto do Lager, é um trabalho humanístico e humanitário, que se faz para diminuir a estranheza do estrangeiro" (SCARPA, 2015, p. 49).

Lefevere (2012) afirma que a tradução é reescrita. A transposição de uma obra literária de um sistema a outro é, consequentemente, a transposição de elementos culturais de uma a outra realidade; é um dos eficazes meios de comunicação entre duas culturas (D’HULST, 2007), capazes de determinar, o cânone da cultura de chegada. Em nosso caso, analisar a primeira recepção de Primo Levi e de sua obra no Brasil, significa analisar os contextos nos quais suas duas primeiras obras foram traduzidas, evidenciando seu caminho editorial, da cultura de partida ao sistema literário e ao leitor brasileiro.

Assim, concebendo a tradução como "a forma mais reconhecível de reescrita e, potencialmente, a mais influente por sua capacidade de projetar a imagem de um autor e/ou de uma (série de) obra(s) em outra cultura, elevando o autor e/ou as obras para além dos limites de sua cultura de origem" (LEFEVERE, 2012, p. 24), algumas questões norteiam a nossa análise: de que modo os títulos traduzidos em questão chegam ao Brasil? Como e quem os traduziu? Qual o público leitor atingido e qual a fortuna crítica gerada? Evidentemente, a apresentação de todo esse panorama, referente a $E$ isto um homem? e Os afogados e os sobreviventes é de suma importância, pois gera subsídios que permitem uma análise mais profunda sobre o papel do autor em nosso universo cultural, intelectual e acadêmico, abarcando a sua influência em vários campos do conhecimento, tais como a sociologia, a antropologia, a história, a química, a psicologia, a ciência política e o direito.

Analisando o histórico de recepção dos escritos de Primo Levi pela crítica, na Itália, podemos considerar três fases, que parecem se construir após o sucesso alcançado por sua obra de estreia, quando publicada pela Einaudi: a primeira tem a ver com a necessidade de evidenciar a qualidade de Levi como escritor e posicioná-lo no cânone da literatura italiana; a segunda pauta-se pela elucidação de Levi como grande escritor além da literatura memorialística e de testemunho, dando destaque a temas diversos, presentes nos gêneros por ele cultivados (contos de ficção científica, poesia, ensaios etc.); a terceira fase de recepção tem como objetivo manter vivo o "efeito-Levi", reagindo contra estereótipos que rotulam a obra do autor como trágica e monotemática, e evidenciando um intelectual engajado que, mediante suas múltiplas faces - químico, testemunha, escritor - ainda tem muita coisa a dizer ao leitor do século XXI: a iminência dos perigos causados pela guerra; a desumanização do indivíduo por meio da mecanização da sociedade; os danos ao meio ambiente e os riscos à espécie humana; a sobrevivência de regimes que reproduzem faces do nazifascismo, entre outras questões presentes em seus ensaios, contos e entrevistas. 
Evidentemente, quando levamos em conta o itinerário de Primo Levi da Itália ao Brasil, observamos também por aqui uma recepção que pode ser considerada tardia, e que aconteceu somente após a morte do autor. Além de seu país, onde é reconhecido definitivamente como grande escritor somente a partir dos anos 1970, a difusão de sua obra pelo mundo acontece somente na década de 1980 , e coincide com dois fenômenos.

O primeiro deles é cultural, e corresponde tanto ao aumento da importância conferida desde o final da década de 1980 aos direitos humanos, seguindo um pensamento universalista e moral e, concomitantemente, ao surgimento da cultura da memória que ocupou o centro das atenções acerca da história do genocídio dos judeus. O segundo fenômeno é exatamente a sua morte e, sobretudo, o espanto causado pela maneira como morreu. Seus biógrafos citam um quadro de depressão, agravado pela falta de medicamentos, cuja administração teve de ser interrompida devido a uma intervenção cirúrgica na próstata. Além disso, a tristeza pela doença da mãe nonagenária, que a fazia totalmente dependente do filho, teria se somado aos outros fatores e o levado a se suicidar, jogando-se da escadaria do prédio onde morava, em 11 de abril de 1987, aos 67 anos de idade. A morte do autor chama a atenção do mundo todo, principalmente pelo modo que se deu. Algumas pessoas, ainda hoje, custam a acreditar que aquele sobrevivente da Shoah, homem que sempre transpareceu lucidez e racionalidade, mesmo nos momentos mais críticos, que havia escrito em um artigo que não entendia o suicídio de Jean Améry, poderia ter tirado a própria vida.

Preponderante para nossa análise não são as conjecturas a respeito da morte de Primo Levi alguns falam de queda acidental e outros até de assassinato -, mas sim o impacto que a morte do autor teve naquele contexto cultural ao redor do mundo. Ao analisarmos os jornais brasileiros, que noticiaram o fato, nos deparamos com textos significativos nesse sentido: o "Obituário" do Jornal do Brasil do dia 12 de abril de 1987, ressaltava que ele era um "possível candidato ao Prêmio Nobel e havia conquistado importantes prêmios italianos na área de literatura"; a Folha de São Paulo falava de uma morte "aparentemente acidental" que estava sendo considerada suicídio pela polícia italiana; e O Estado de São Paulo noticiava a morte de Primo Levi em uma coluna do dia 14 de abril de 1987, em uma das páginas de seu "Caderno 2".

As notas sobre a morte de Levi são, na verdade, parte daquilo que podemos considerar as primeiras citações ou referências ao autor em nosso ambiente cultural. A obra do autor começara a suscitar interesse definitivo após o sucesso que alcançara nos Estados Unidos, com a publicação da tradução de Il sistema periodico, no final de 1984. Apesar de ter alguns de seus livros já traduzidos para o público de língua inglesa - If this a man (1959) e The truce (1965) -, foi somente com a publicação de The periodic table, pela editora Shocken Books e com tradução de Raymond Rosenthal que Primo Levi conquistou os leitores anglófonos. As entusiasmadas resenhas do escritor Saul Bellow chamaram a atenção e foram responsáveis por uma recepção positiva que ultrapassou os limites da literatura e alcançou, de maneira ainda mais intensa, o universo da ciência.

Considerando o mundo ibérico e latino-americano em geral, as traduções para o espanhol e 
para o português começaram a circular somente após a morte do autor, primeiro na Espanha, e depois em Portugal, em 1988. Enquanto observamos que as traduções espanholas são aquelas que circulariam nos países hispânicos da América Latina durante muito tempo - salvo uma rara edição argentina de Se questo è un uomo - o mesmo não acontece com as edições portuguesas em relação ao Brasil. Os caminhos editoriais que levam Primo Levi ao leitor português são diferentes daqueles que o trazem ao leitor brasileiro.

A primeira edição brasileira de uma obra de Levi foi lançada em 1988, pela Editora Rocco, com tradução de Luigi Del Re. Com o título É isto um homem?, a obra chegou ao Brasil cerca de um ano após a morte do autor - e mais de quarenta anos depois da primeira edição italiana. I sommersi e i salvati, seu último livro, por sua vez, apareceu em nosso sistema literário em 1990, apenas quatro anos após o lançamento na Itália, publicado aqui pela Editora Paz e Terra, com tradução de Luiz Sérgio Henriques: Os afogados e os sobreviventes: os delitos, os castigos, as penas, as impunidades. Ambas podem ser consideradas marcos iniciais de uma recepção mais substanciosa dos escritos de Primo Levi, e geradoras de uma considerável fortuna crítica, ainda que tardia.

O nome de Primo Levi figurava em artigos, notícias e notas jornalísticas, mesmo antes da sua morte e das primeiras publicações de suas obras por aqui. Levi era tido ora como grande nome da literatura italiana do século XX, ora como intelectual participativo nos assuntos contemporâneos, ora como referência fundamental no testemunho da Shoah. E, de fato, ele era tudo isso. Entre o final dos anos 1970 e início dos anos 1980, período em que seu nome começa a figurar na imprensa brasileira, nas páginas de cultura ou de notícias internacionais, as entrevistas de Levi na Itália são cada vez mais frequentes e, por isso, sua voz e sua opinião a respeito de vários temas são ouvidas. Além disso, o autor assumia definitivamente em seu país o papel de intelectual engajado, tornando-se colaborador fixo do jornal La Stampa, e colaborando com seus escritos em outros grandes jornais.

Dessa forma, as primeiras aparições do nome do autor em nossos veículos de imprensa são do final da década de 1970. A primeira referência direta é de uma notícia do jornal $O$ Estado de São Paulo, de 10 de maio de 1978. Com a manchete "O fim de uma agonia de 55 dias", o texto falava sobre o corpo do primeiro-ministro italiano Aldo Moro, que havia sido encontrado no porta-malas de um automóvel no centro de Roma no dia anterior, e trazia uma declaração de Levi, qualificado como um "escritor que conheceu os campos de concentração nazistas": "Sinto um pesar tremendo por este fim atroz, e também um sentimento de raiva ante a incapacidade de nossas autoridades".

Algumas semanas depois, o jornal O Estado de São Paulo trazia em seu suplemento literário um artigo sobre a literatura italiana, assinado pela professora Loredana Caprara. Com a manchete "Os rumos da narrativa italiana", o artigo apresenta ao leitor três "novos" nomes da narrativa italiana do Novecento: Elio Vittorini, Primo Levi e Cesare Pavese, trazendo fotos dos três e destacando, naquela de Levi, a literatura sobre os campos de concentração. 
Durante a década de 1980 o nome de Primo Levi figuraria em outras citações em alguns dos mais importantes jornais que circulavam nas capitais brasileiras. Em São Paulo, sobretudo o Estado, trouxe algumas matérias nas quais o nome do escritor italiano aparecia. Em uma das mais significativas, em 15 de junho de 1980, na apresentação da "nova seção" do jornal, o caderno "Cultura", o editor cita o intercâmbio com publicações internacionais de renome, como a NY Times Book Review, da qual traz como contribuição um artigo assinado por Frank McShane: “A nova literatura na Itália”. O artigo aborda os autores italianos que, a partir da década de 1950, se inseriram no cânone daquele país, citando nomes como Alberto Moravia, Natalia Ginzburg e Primo Levi, e traçando um bom panorama da literatura, da sociedade e do mercado editorial italiano.

Evidentemente, o impacto da obra de Levi no ambiente cultural e intelectual brasileiro, nesse momento, era praticamente nulo. As referências a seu nome eram mínimas e irrelevantes para nosso contexto, pelo que depreendemos da pesquisa feita nos acervos dos principais periódicos que circulavam na década de 1980 e que traziam reportagens significativas sobre autores estrangeiros em seus cadernos de cultura. Mesmo as matérias que tratavam do autor e de seus escritos traziam a imagem primeira de um químico que sobreviveu à tragédia e escreveu seu testemunho. Em outros casos, traziam a opinião política de Levi que nessa época, na Itália, como já dissemos, tinha a imagem consolidada de intelectual engajado. Em matéria de 25 de setembro de 1982, o Estado de São Paulo trouxe uma reportagem sobre o crescimento do antissemitismo na Itália, citando fatos ocorridos após a invasão do Líbano por Israel e o crescimento de manifestações contra o governo do primeiro-ministro israelense Menachem Begin. A reportagem cita uma declaração de Levi $^{2}$, dada ao jornalista Giampaolo Pansa e publicada no jornal La Repubblica, um dia antes.

Uma matéria que faz referência ao autor, de 29 de janeiro de 1984, é significativa para se pensar a questão da recepção da literatura italiana no Brasil, de modo geral. O artigo intitulado "Literatura Italiana, um universo para se descobrir", de autoria de Federico Mengozzi, e publicado pelo mesmo $O$ Estado de São Paulo, expõe que as relações entre a literatura italiana e o mercado editorial brasileiro são "pouco amistosas" e, por isso, as traduções são raras. O espaço de publicação dessas traduções se amplia, segundo ele, após a tradução $O$ nome da rosa, best-seller de Umberto Eco, lançada pela Nova Fronteira em 1983. O autor cita ainda o crítico Franklin de Oliveira, segundo o qual, existe um desinteresse dos editores brasileiros pela cultura italiana. A matéria se encerra ressaltando autores ainda não traduzidos, como era o caso de Levi, e com uma referência direta a Pirandello: "Literatura Italiana? Mais de seis escritores à procura de um editor brasileiro".

O período imediatamente anterior ao lançamento do primeiro livro de Levi no Brasil, conta com o mais significativo texto do autor traduzido para o português até aquele momento.

2 Em 1982 são numerosas as declarações de Levi sobre o conflito no Oriente Médio, especialmente sobre aqueles que envolviam o Estado de Israel. A citada entrevista a Giampaolo Pansa se intitula "Io, Primo Levi, chiedo le dimissioni di Begin". In: LEVI, 2018, p. 303-309. 
A célebre conversa/entrevista com o também escritor Philip Roth ${ }^{3}$, publicada em $O$ Estado de São Paulo, no dia 03 de janeiro de 1987, com a manchete "Primo Levi, um homem de múltiplas habilidades", iria ser, mais tarde, um dos textos do cânone do autor. A conversa entre os dois é fruto de dois encontros: o primeiro aconteceu em abril de 1986, em Londres - a segunda viagem de Levi a um país de língua inglesa depois de se tornar um escritor conhecido (ele estivera nos Estados Unidos um ano antes) -, e o segundo em um fim de semana de setembro daquele mesmo ano, em Turim, quando o escritor estadunidense foi oficialmente entrevistá-lo para a revista nova-iorquina.

A versão que saiu no jornal brasileiro é a primeira, originalmente publicada em inglês pela NY Times Book Review em 12 de outubro de 1986. A entrevista teria ainda mais duas versões: uma, em italiano, publicada pelo La Stampa em duas partes, nos dias 26 e 27 de outubro de $1986^{4}$, onde consta uma pergunta a mais; e outra, publicada originalmente por Roth em livro de 2001, chamado Shop Talk, onde constam algumas adequações e correções. A obra foi traduzida para o português em 2008, com o título Entre nós, pela editora Companhia das Letras. Nas três versões do mesmo texto estão mudanças importantes, mas não decisivas, que fazem parte da análise e de habituais reconsiderações e releituras de Roth.

Traçar o caminho editorial de uma obra, do sistema literário de partida ao sistema literário de chegada, considerando os contextos nos quais ela se insere, nem sempre é tarefa fácil. No caso das duas primeiras obras de Primo Levi traduzidas para o sistema literário brasileiro, optamos por considerar os antecedentes já apresentados, isto é, as primeiras citações e referências ao nome do autor presentes sobretudo nos cadernos de cultura dos principais veículos da imprensa brasileira. Tais fontes são as únicas disponíveis, já que, no âmbito acadêmico e intelectual, Levi só apareceria durante a década de 1990 e, muito mais frequentemente, a partir dos anos 2000.

Partindo da investigação sobre a primeira tradução que figurou entre nós, destacamos a já citada relação entre autor e tradutor, tão cara a Levi. Uma carta do tradutor da obra, Luigi Del Re, evidencia esse contato e, de certa forma, nos apresenta a participação direta de Primo Levi no processo que o trouxe até o leitor brasileiro. A carta escrita em italiano (e por nós traduzida), que se encontra no Fondo Einaudi, junto ao Arquivo de Estado de Turim, foi enviada de Porto Alegre para o autor, em 15 de setembro de 1985, e pressupõe uma anterior troca de correspondência entre os dois.

Assim se inicia a carta de Del Re:

Caro Doutor Levi,

Agradeço a sua carta. Se fosse por mim, começaria imediatamente a traduzir o seu livro, mas escutarei o seu conselho. Tenho aqui em Porto Alegre um velho amigo que sempre trabalhou no setor editorial e que conservou boas relações. Ontem fui encontrá-lo. Ficou de boca aberta ao ouvir sobre as quinhentas mil cópias: é incrível

3 A entrevista dada por Levi a Philip Roth conta com diferentes versões aqui citadas. Belpoliti destaca que entre a versão publicada pela NY Times Book Review, aquela publicada pelo La Stampa e a publicada em volume por Roth, primeiro em Shop talk (2001) e depois em Why write? Collected Nonfiction 1960-2013 (2017) há algumas diferenças no que diz respeito ao número de perguntas, conteúdo e cortes. No terceiro volume das obras completas de Levi, lançado em 2018, Belpoliti publicou as respostas escritas pelo autor italiano ao colega estadunidense com o nome de "Risposte a Philip Roth". (LEVI, 2018, p. 1074-1091).

4 Essa versão é a que está traduzida para o português e constitui o apêndice à tradução brasileira de Il sistema periodico. In: LEVI, 1994, p. 235-244. 
que "Se questo è un uomo" não seja conhecido aqui (assim que ouviu "Levi" pensou em Carlo Levi, de quem "Cristo si è fermato a Eboli" foi traduzido tanto em português quanto em espanhol). Ele me disse que seria bom levar à editora uma cópia do livro, e talvez também uma cópia da edição escolar, da qual o senhor me fala. Segundo ele, seria conveniente também algum comentário ou resenha.

Parece-me um pouco ridículo pedir ao senhor uma resenha de "Se questo è un uomo", uma vez que se trata de uma obra muito conhecida, mas estamos no Brasil, e não na Itália. Recordo-me, por exemplo, de uma entrevista do senhor publicada há alguns anos pelo Corriere della Sera; se eu a tivesse, bastaria para provar a notoriedade do autor. Enfim, se o senhor puder me mandar algo, tudo bem; se não, sem problemas.

O que me parece essencial é que a Einaudi, junto com a "Chiave a stella" (e obrigado, por enquanto), me envie um par de cópias do livro. Eu tenho só uma e não gostaria de emprestá-la: além de estar junto de "La tregua" e de faltar aquele "posfácio" do qual o senhor fala, está cheia de anotações e tem, colada dentro, uma poesia sua ("Dateci").

\section{(...)}

Alguns pontos são interessantes na missiva: o primeiro é que, de fato, Primo Levi não era um autor conhecido no Brasil, apesar de já ter vendido cerca quinhentas mil cópias na Itália; o segundo é o desejo de Del Re em traduzir para o português uma obra que tanto o marcou pessoalmente, tanto que faz referência a uma citação de Se questo è un uomo em um suposto "segundo livro" no qual estava trabalhando5; o terceiro é a evidência de que Del Re conhecia outros escritos do autor que, até aquele momento, não encontravam nenhuma ressonância no Brasil, casos de A chave estrela ${ }^{6}$ e do poema "Dai-nos"7; o quarto, e talvez mais importante, é que Del Re cita que tinha em seu poder uma edição de Se questo è un uomo junto com La tregua. Tal edição, lançada pela Einaudi na coletânea "Supercoralli", em 1972, não apresentava o apêndice, ao qual autor e tradutor se referem na carta como "posfácio", e que só iria integrar a obra a partir de 1976. Isso talvez explique o pedido de Del Re à editora por novas cópias do livro que desejava traduzir e, principalmente, o motivo pelo qual o apêndice, um importantíssimo texto do autor, não consta na edição brasileira até hoje.

A mensagem indica que Del Re havia, em um contato anterior, pedido a autorização de Levi para que pudesse traduzir Se questo è un uomo. Levi teria dito a ele para que antes procurasse um editor interessado em publicar a obra, para depois, efetivamente, proceder à tradução. Tudo se confirma por uma carta de 25 de abril de 1988, enviada pelo tradutor à família do autor, um ano após a sua morte. Nela, Del Re afirma que "em 1985 havia escrito ao Dr. Levi, pois não conseguia encontrar no Brasil 'Se questo è un uomo' (que gostaria de apresentar a muitos amigos) e perguntava se seria possível a publicação em português". Ele indica que Levi o respondeu por meio de "uma carta muito cordial, na qual dizia que o livro não tinha sido traduzido ainda", mas o desaconselhava a traduzir a obra antes de encontrar um editor. $\mathrm{Na}$ sequência, ele escreve que uma editora do Rio de Janeiro - infelizmente, não podemos afirmar

5 Luigi Del Re, italiano radicado no Brasil, romancista, cronista e tradutor, escreveu três livros: o primeiro, o romance Attesa a Guatambù, publicado pela Mondadori, em 1983; o segundo, um livro de crônicas de viagens intitulado Pelos caminhos da Patagônia, da editora Mercado Aberto, de 1994; e o terceiro, um livro de memórias sobre o filho, Bruno e os elefantes-marinhos, publicado pela editora Record, em 2006. Na carta, Del Re cita o livro editado pela Mondadori, em 1983 e um "segundo livro", o qual não podemos afirmar com certeza que seja aquele lançado somente em 1994, ou outro que possa não ter sido publicado.

6 A versão brasileira da obra seria publicada somente em 2009, com tradução de Maurício Santana Dias.

$7 \quad$ Uma antologia dos poemas de Levi traduzidos foi publicada somente este ano, em 2019. 
com certeza qual seja - tinha lhe assegurado que publicaria a tradução, mas isso não chegou a acontecer. E afirma que somente naquele ano, 1988, a editora Rocco decidira publicar o livro e confiou-lhe a tradução. Ele ressalta ainda que, "quando escreveu ao Dr. Levi, pensava não somente no significado do livro no Brasil, mas também na possibilidade de a tradução colocá-lo em contato direto com o autor".

$\mathrm{Na}$ mesma carta, demonstrando conhecimento de traduções da obra em outros idiomas, Del Re indica a possibilidade do título em português, É isto um homem?, que expõe o questionamento presente no título original mediante o ponto de interrogação, e sem o "se" condicional, que figura, por exemplo, na edição portuguesa: "gostaria de saber o que ele pensava do título, que aqui poderia ser 'É isto um homem' - ou seja, é, isto (isto como neutro, quase como 'esta coisa') um homem? Vi que na edição alemã foi escolhido esse caminho ('Ist das ein Mensch?')". Como sabemos, esse foi de fato o título escolhido e publicado pela Rocco.

Após a morte de Primo Levi, todas as correspondências entre autor e editor encontradas no arquivo pesquisado eram endereçadas e respondidas pela sua esposa, Lucia Levi. Em uma delas, de 22 de maio de 1985, Lucia indica algumas negociações para traduções e publicações de obras do marido e, no final, faz referência à última carta de Del Re: "envio também a cópia de uma carta que recebi hoje do Brasil (...). Agradecerei esse senhor, mas acredito que já existam contratos com o Brasil". De fato, o contrato com o Brasil já existia, e era exatamente aquele ao qual o tradutor faz referência.

O papel de Lucia Levi após a morte do autor é muito interessante, inclusive para que possamos lançar luz sobre as duas primeiras traduções brasileiras. Ativamente, ela participa das discussões sobre traduções, publicações e adaptações - em uma das cartas ela interage com o diretor Francesco Rosi, que seria responsável pela adaptação cinematográfica de A trégua, estreado em 1997.

Em carta de 30 de março de 1988, enviada pela Einaudi a Lucia, faz-se referência ao contato da editora Teorema, que desejava publicar em Portugal a tradução de Se questo è un uomo. Duas editoras portuguesas - Dom Quixote e Gradiva - que haviam publicado, respectivamente, Se non ora, quando? e Il sistema periodico, tinham declinado da preferência em editar a obra de estreia do autor. A responsável pela negociação por parte da Einaudi, Patrizia Varetto, ressalta na carta que era preferível não dispersar as obras de Levi por várias editoras diferentes e que, se Lucia quisesse negar a proposta, poderia ficar à vontade. Na resposta, Lucia dá o consentimento para a publicação, que sairia em Portugal em 1988, com o título de Se isto é um homem, e tradução de Simonetta Cabrita Neto. Interessante é o fato da esposa de Levi manter-se fiel às premissas do marido no que diz respeito às traduções de sua obra: na mesma resposta, ela diz que espera que o editor tenha dado garantia de seriedade e que "seria bom se houvesse a possibilidade de rever a tradução: alguns primos de Levi viveram muito tempo no Brasil e, talvez, 
poderiam dar um parecer sobre a fidelidade da tradução" ${ }^{8}$.

Em outra correspondência, dessa vez de 13 de novembro de 1988, Lucia coloca nas mãos da editora os parâmetros para a negociação com o editor brasileiro "Paz e Terra". Apesar de não termos tido acesso à carta da editora para Lucia, de 08 de novembro, como ela indica, provavelmente trata-se da negociação pelos direitos de I sommersi e $i$ salvati para o Brasil. Mais uma vez ela demonstra preocupação com a transposição do texto do italiano para o português, criticando uma edição lusitana de Se non ora, quando?: "Desejaria, porém, que a senhora pedisse, como de costume, de poder rever a tradução: um primo de Levi, que viveu muito tempo no Brasil gentilmente se disponibilizaria. Isso porque na edição portuguesa de SE NON ORA, QUANDO? os erros de tradução são numerosíssimos".

Em 23 de maio de 1989, a Einaudi envia outra correspondência à esposa de Levi, com a oferta da editora Rocco também para a publicação de I sommersi e $i$ salvati, indicando que a editora era confiável, e estava interessada em publicar mais obras de Primo Levi no Brasil. Partindo do fato de que a casa editorial brasileira tinha sido responsável pela publicação de É isto um homem?, e que a obra atingira determinado sucesso de público, podemos considerar que o interesse em continuar publicando as obras do autor existia, de fato. Porém, como sabemos, o último livro de Levi foi publicado no Brasil pela Paz e Terra, no ano seguinte, o que nos leva a crer que havia a negociação, em 1989, com dois editores brasileiros interessados na publicação, e que a Paz e Terra ganhou a preferência, ou por parte da editora, ou por parte da família de Levi.

É isto um homem? foi lançado pela Rocco em novembro de 1988, três anos após a troca de correspondências entre Del Re e Levi. O livro conta com algumas reimpressões e reedições, o que evidencia a inserção do autor e o seu importante papel dentro do sistema literário nacional e, consequentemente, indica sua importância no ambiente cultural e intelectual de chegada. Além da edição de 1988, foram mais duas reimpressões (2000 e 2013) nas quais, salvo as mudanças na capa e configurações das páginas, não há nenhuma alteração no conteúdo: encontramos o prefácio do autor, bem como a poesia "Shemá", anteriores ao primeiro capítulo. Apesar de as informações sobre copyrights presentes na ficha catalográfica citarem tanto a edição de 1958, quanto a de 1976, ambas da Einaudi, não há na edição brasileira o apêndice com as perguntas e respostas, que Levi inclui na obra em 1976, e que configuram um importante documento.

Em 06 de maio de 1989, um hoje conhecido artigo de Primo Levi, originalmente intitulado "Dello scrivere oscuro", presente no volume L'altrui mestiere, é publicado n'O Estado de São Paulo. O artigo indica como origem a publicação do N.Y. Times Book Review. Intitulado, no Brasil, "Acima de tudo: ser claro", traz um pequeno texto explicativo: "Considerado pela crítica um dos melhores escritores italianos contemporâneos, Primo Levi, que morreu em 1987, tornou-se conhecido por seu livro 'Se isto é um homem', um relato dos horrores que viveu em Auschwitz. Neste ensaio, que faz parte do livro recentemente lançado nos Estados Unidos, com

8 Alguns tios e primos de Primo Levi, em 1938, refugiaram-se no Brasil após a implantação das leis raciais na Itália. Em 20 de fevereiro de 2019 foi publicada pelo jornal La Stampa uma carta inédita do autor, enviada a esses parentes logo após ter retornado do Lager, em novembro de 1945. Trata-se efetivamente de um dos primeiros escritos do autor sobre o campo de concentração, e apresenta as características de estilo detectadas em sua obra de estreia. No Brasil, a carta foi traduzida por Aislan Camargo Maciera e Maurício Santana Dias, e publicada na edição 247 da revista Cult, em julho de 2019, com o título "Não éramos mais homens". 
o título 'Other People's Trade', o escritor analisa o ato de escrever e recomenda a clareza como condição necessária para a comunicação". O artigo foi, ao que tudo indica, traduzido do inglês para o português ${ }^{9}$.

Os afogados e os sobreviventes: os delitos, os castigos, as penas, as impunidades foi lançado pela editora Paz e Terra entre agosto e setembro de 1990, e conta hoje com mais duas reimpressões, uma de 2004 e outra de 2016. O título pelo qual o tradutor Luiz Sérgio Henriques optou é a reprodução de título e subtítulo que aparecem na edição original da obra, publicada pela Einaudi na coleção "Gli struzzi”. A chegada da obra ao mercado editorial brasileiro apresenta diferenças em relação ao livro por aqui publicado anteriormente: em primeiro lugar, já não se tratava de um autor desconhecido, já que o seu livro de estreia, ao que tudo indica, havia atingido um número considerável de leitores e tido ressonância em diversos meios culturais; em segundo lugar, tratava-se de uma obra bem mais recente, que teve seu sucesso impulsionado pela morte do autor, e que contava com uma recepção mais atual e numerosa.

Observando as nossas fontes, muitas vezes os artigos publicados no Brasil sobre Primo Levi, antes das primeiras publicações ou em torno delas, são traduções de artigos publicados primeiramente nos Estados Unidos. Notamos que a NY Times Book Review era uma grande referência, sobretudo para os escritos que figuravam no jornal $O$ Estado de São Paulo. Isso nos faz levantar a hipótese, extremamente consistente, de que o caminho de Primo Levi, até chegar ao Brasil, passou antes pelo país da América do Norte. Não podemos deixar de considerar a influência de publicações do autor nos Estados Unidos que, como se nota em alguns casos, serviu como intermediário entre os sistemas literários de partida, a Itália, e de chegada, o Brasil. Tal intermediação não se deu de maneira direta, isto é, não se trata de traduções feitas a partir das versões em inglês, já que os dois primeiros livros de Levi que figuraram no mercado editorial brasileiro foram vertidos diretamente do italiano. Mas trata-se de uma intermediação indireta, através da qual podemos notar a influência do ambiente intelectual e cultural estadunidense em nosso contexto cultural.

A publicação da segunda obra de Levi no Brasil parece inseri-lo definitivamente em nosso panorama literário. É crescente o número de referências ao autor, tanto no jornalismo cultural, quanto nos ambientes acadêmicos. A década de 90 é responsável por consolidar o nome de Primo Levi no cânone da cultura de chegada, e dará origem a mais três edições de obras traduzidas: A tabela periódica, da editora Relume-Dumará, com tradução de Luiz Sérgio Henriques, de 1994; A trégua, da editora Companhia das Letras, com tradução de Marco Lucchesi, em 1997; Se não agora, quando?, da mesma Companhia das Letras, agora com tradução de Nilson Moulin, de 1999. Todas as obras contariam com novas reimpressões ou edições na primeira década do século XXI, sempre pelas mesmas editoras e com a mesma tradução.

Nos anos 2000, além das traduções cada vez mais numerosas, a ressonância da obra de Primo Levi nos vários ambientes culturais e acadêmicos chama a atenção. Um grande número de artigos acadêmicos é publicado, as aparições nos cadernos de cultura dos principais jornais

9 O texto italiano foi publicado pela primeira vez em La Stampa, em 11 de dezembro de 1976. A versão em português, traduzida diretamente do italiano, só apareceria no volume $O$ ofício alheio, publicado pela Editora Unesp, em 2016, com tradução de Silvia Massimini Felix. 
intensificam-se consideravelmente, e o surgimento de revistas especializadas em cultura faz com que Levi assuma definitivamente seu papel no contexto literário brasileiro: químico, deportado, testemunha, sobrevivente, escritor, intelectual. São as várias faces de um autor que ainda tem muito a dizer ao leitor do século XXI. 


\section{Referências bibliográficas}

D'HULST, Lieven. Comparative Literature versus Translation Studies: Close Encounters of the Third Kind? European Review, Cambridge, v.15, n.1, p. 95-104, jan. 2007.

GOLDSTEIN, A.; SCARPA, D. In un'altra lingua. Torino: Einaudi, 2015.

LEVI, P. Opere complete. A cura di Marco Belpoliti. Torino: Einaudi, 2016, v. 1 e v. 2. . Opere complete. A cura di Marco Belpoliti. Torino: Einaudi, 2018, v. 3.

. A chave estrela. Trad. Maurício Santana Dias. São Paulo: Companhia das Letras, 2009. . A trégua. Trad. Marco Lucchesi. São Paulo: Companhia das Letras, 1997. . A tabela periódica. Trad. Luiz Sergio Henriques. Rio de Janeiro: Relume-Dumará, 1994. . È isto um homem? Trad. Luigi del Re. Rio de Janeiro: Rocco, 2013. . Mil sóis. Trad. Maurício Santana Dias. São Paulo: Todavia, 2019. . "Não éramos mais homens". Trad. Aislan Camargo Maciera e Maurício Santana Dias. In: Cult, São Paulo: XXII (247): p. 38-39, jul. 2019. . Os afogados e os sobreviventes. Trad. Luiz Sergio Henriques. São Paulo: Paz e Terra, 2016.

. O ofício alheio. Trad. Silvia Massimini Felix. São Paulo: Unesp, 2016.

LEFEVERE, A. Tradução, reescrita e manipulação da fama literária. Trad. Claudia Matos Seligmann. Bauru: Edusc, 2007.

Recebido em: 05/10/2020

Aprovado em: 11/11/2020 